\title{
DEVELOPMENT OF TOLERANCE AND A NEW CORONARY VASODILATOR, N-(2-HYDROXYETHYL) NICOTINAMIDE NITRATE (SG-75): A COMPARISON WITH NITROGLYCERIN
}

\author{
Hiroyuki NABATA, Yasuyuki SHIRAKI and Kazushige SAKAI \\ Department of Pharmacology, Research Laboratories, Chugai Pharmaceutical Co.. Ltd., \\ Takada, Toshima-ku, Tokyo 171, Japan
}

Accepted March 1,1981

\begin{abstract}
Tolerance to $\mathrm{N}$-(2-hydroxyethyl)nicotinamide nitrate (SG-75) and nitroglycerin (NTG) was studied in rats with regard to the blood pressure responses in vivo and thoracic aorta strip preparations in vitro. Tolerance to the blood pressure response to SG-75 or NTG was observed with consecutive subcutaneous administrations of high doses of SG-75 or NTG. three times a day and the tolerance was time- and dose-dependent. In strips of the aorta incubated for 30 min with SG-75. sensitivity to challenging doses of SG-75 remained unchanged, but in the preparations incubated with NTG, the response to challenging doses of NTG was greatly decreased. SG - 75 developed no cross tolerance to NTG. In in vivo experiments, SG-75 developed only slight tolerance, but in the in vitro experiments, unlike NTG. induced no tolerance.
\end{abstract}

$\mathrm{N}$-(2-hydroxyethyl) nicotinamide nitrate (SG-75) is a potent new coronary vasodilator (1-4) under development as a potential anti-anginal drug. The pharmacological profile is partly similar to that of nitroglycerin (NTG) (4). The problem of tolerance to organic nitrates such as NTG has been given attention since the first clinical report of NTG therapy for hypertension (5). Current studies have demonstrated that tolerance to NTG is developed not only in humans (6-7). but also in rats (8), rabbits $(9-10)$ and dogs (11-12). Furthermore, NTG induces crosstolerance to other organic nitrates (9). According to the hypothesis of Needleman and Johnson (9), organic nitrate tolerance involves the oxidation of a critical sulfhydryl group in the NTG "receptor" and the release of inorganic nitrite. The chemical structure of SG-75 includes the nitrate moiety. It seems that this moiety plays an essential role in the pharmacological activity $(3,13)$.

Our aim was, therefore, to determine whether or not a tolerance to SG-75 would be induced and for this purpose blood pressure responses and vascular smooth muscle relaxation were monitored in rats.

\section{MATERIALS AND METHODS}

Male Sprague-Dawley rats weighing 350 to $720 \mathrm{~g}$ were used.

Blood pressure measurements: The animals were anesthetized with sodium pentobarbital $(70 \mathrm{mg} / \mathrm{kg}$, i.p.). Systemic blood pressure was measured with a pressure transducer (Nihon Kohden, MPU-0.5) by inserting a polyethylene cannula into the carotid artery and the pressure was recorded on a rectilinear recorder (Nihon Kohden, WI-680G). Needleman (8) reported that a single s.c. administration of NTG $10 \mathrm{mg} / \mathrm{kg}$ to rats lowered the blood pressure by about 
$40 \%$, and that tolerance developed when s.C. administration of NTG at $10 \mathrm{mg} / \mathrm{kg}$ three times a day (daily $30 \mathrm{mg} / \mathrm{kg}$ ) was continued. As we found that the depressor effects of a single injection of $3 \mathrm{mg} / \mathrm{kg}$ or $10 \mathrm{mg} / \mathrm{kg}$ of SG-75 correspond to those of $10 \mathrm{mg} / \mathrm{kg}$ of NTG, a single dose of SG-75 (3 or $10 \mathrm{mg} / \mathrm{kg}$ ) or NTG (10 mg/kg) respectively. was given s.c., three times daily (SG-75 9 or $30 \mathrm{mg} / \mathrm{kg}$ s.C. and NTG $30 \mathrm{mg}$ / $\mathrm{kg}$ s.c. as daily doses), at 10 a.m. and at 2 and 6 p.m., daily for 1 to 8 days to establish tolerance. Since a concentrated alcohol solution of NTG was used for the s.c. infusate, control rats were given as S.C. administration of $99.5 \%$ alcohol $(0.05 \mathrm{ml} /$ $100 \mathrm{~g}$ body weight), three times daily for 8 days. In the SG-75- and NTG-pretreated animals, 16 to $18 \mathrm{hr}$ after the last drug administration blood pressure responses to SG-75 and NTG given i.v., respectively were examined. Here, SG-75 or NTG was given into the femoral vein.

Vascular smooth muscle preparations: The animals were killed by a blow on the head and the thoracic aortae quickly removed. A spiral strip, $2 \mathrm{~cm}$ long and 4-5 $\mathrm{mm}$ wide, was suspended in a $10 \mathrm{ml}$ organ bath at $37^{\circ} \mathrm{C}$ containing Tyrode solution and aerated with $95 \% \quad \mathrm{O}_{2}: 5 \% \quad \mathrm{CO}_{2}$. The strip preparations were equilibrated under $0.8 \mathrm{~g}$ of tension for $2 \mathrm{hr}$ before the start of experiments. During the equilibration period, the medium was replaced every 15 to $20 \mathrm{~min}$. Cumulative dose-response curves for muscle relaxation of SG-75 or NTG were generated after contraction with $6 \times 10^{-6} \mathrm{M}$ norepinephrine (Nor). This concentration of Nor yields a contraction about $80 \%$ of the maximal. For induction of tolerance or cross tolerance, the strips were incubated in $10 \mathrm{ml}$ of Tyrode solution bubbled with $95 \%$ $\mathrm{O}_{2}: 5 \% \mathrm{CO}_{2}$ at $37^{\circ} \mathrm{C}$ for $30 \mathrm{~min}$ in the presence of SG-75 or NTG, thereafter washed three times and then dose-response curves for

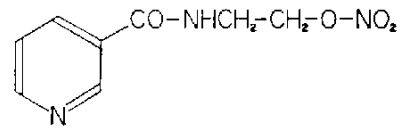

Fig. 1. Chemical structure of $N-(2-$ hydroxyethyl) nicotinamide nitrate ester (SG-75)

SG-75 or NTG were constructed. A different piece of aortic strip was used for each experiment. Changes in tone of arterial strips were measured using an isotonic transducer (MEC. Model ME-4031). Recordings were made isotonically on an ink-writing pen recorder (TOA Denpa, CDR-12A). The values of $\mathrm{pD}_{2}$ and $\mathrm{pD}_{5}$ respectively, were defined from the concentration of drugs which induced a relaxation of $50 \%$ and $20 \%$ of the Nor-induced muscle contraction (14).

Drugs used were as follows: N-(2hydroxyethyl) nicotinamide nitrate ester (SG75) (synthetized in Chugai Organic Chemical Research Laboratory, see Fig. 1), nitroglycerin (kindly provided by Nihon Kayaku Co., Tokyo; dissolved in $99.5 \%$ ethyl-alcohol at a concentration of $20 \mathrm{mg} / \mathrm{ml}$ ), norepinephrine hydrochloride (Sankyo) and histamine dihydrochloride (Wako Junyaku). SG75 was dissolved in $0.9 \%$ saline and NTG was diluted with $0.9 \%$ saline. For blood pressure experiments, S.c. and i.v. infusates were $0.05 \mathrm{ml}$ per $100 \mathrm{~g}$ body weight. For the experiments of smooth muscle strips, drug solutions were added to the bath in a volume of $0.1 \mathrm{ml}$ using individual syringes.

Values in the text are represented as means $\pm S E$. The statistical significance of the differences between mean values was evaluated by Student's $t$-test and considered to be significant when $P$ values were less than 0.05 .

\section{RESULTS}

Tolerance and blood pressure effects of SG-75 and NTG: Sixteen to eighteen hr after the last drug administration, SG-75 and NTG were given i.v. to the rats pretreated 
Table 1. Initial values of blood pressure at 16 to $18 \mathrm{hr}$ after the last drug administration

\begin{tabular}{cccc}
\hline Drugs & $\begin{array}{c}\text { Dose } \\
(\mathrm{mg} / \mathrm{kg})\end{array}$ & $\begin{array}{c}\text { Period of } \\
\text { administration } \\
\text { (days) }\end{array}$ & $\begin{array}{c}\text { Blood pressure } \\
(\mathrm{mm} H \mathrm{Hg})\end{array}$ \\
Control & - & 1 & $\frac{130.4 \pm 5.6}{129.1 \pm 7.1}$ \\
\hline & 3 & 4 & $118.4 \pm 9.1$ \\
SG-75 & & 8 & $120.0 \pm 9.5$ \\
& 10 & 1 & $115.7 \pm 8.7$ \\
& & 4 & $119.7 \pm 8.5$ \\
Nitroglycerin & & 8 & $148.2 \pm 6.3$ \\
\hline
\end{tabular}

Values are mean \pm S.E. and each group consisted of 8 rats. Values are not significantly different from the controls.

chronically (s.c.) with SG-75 and NTG. respectively. Initial values prior to the administration of these doses of each drug are shown in Table 1. There were no significant differences between the corresponding values obtained from the non-treated group (control) and the group treated with SG-75 or NTG. Continued administration of SG-75 (3 mg/ $\mathrm{kg}$ s.c., three times a day) slightly decreased the responsiveness of blood pressure to SG -75 given i.v. over an 8 day period (Fig. 2). The dose-response curves for blood pressure decrease slightly but significantly shifted to the right, and the shift was dependent upon the period of drug administration. To elicit a $20 \%$ fall of mean blood pressure, a 2.5 -fold increase in the dose of SG-75 was required in the group pretreated with SG-75 $(3 \mathrm{mg} / \mathrm{kg}$. s.c.) during 8 days, as compared with the control group. Chronic treatment with $10 \mathrm{mg} /$ $\mathrm{kg}$ s.c. of SG-75, three times daily $\times 8$ shifted only 2.7 -fold to the right the dose-response curve to SG-75 given i.v. On the other hand, the vasodepressor effect of histamine $(10 \mu \mathrm{g} / \mathrm{kg}, \mathrm{i} . \mathrm{v}$.) was as follows: Control, $-20.8 \pm 2.8 \%(\mathrm{~N}=6)$; SG -75 ( $3 \mathrm{mg} / \mathrm{kg}$ s.c., three times daily $\times 8)$-treated rats, -22.7 $\pm 3.5 \%(\mathrm{~N}=7)$ : SG $-75(10 \mathrm{mg} / \mathrm{kg}$ s.c., three times daily $\times 8)$-treated rats, $-16.3 \pm 3.8 \%$ $(N=6)$. There were no significant differences between the corresponding values obtained from the non-treated group (control) and the groups treated with SG-75.

As shown in Fig. 3, tolerance to NTG developed with chronic treatment with 10 $\mathrm{mg} / \mathrm{kg}$ s.c. of NTG given three times a day. The dose-response curves to doses of NTG shifted markedly to the right, and in the group treated with NTG for 4 days a 55 -fold increase in the doses of NTG was required to produce a $20 \%$ decrease in the mean blood pressure. No significant changes were observed between the corresponding values for blood pressure decrease caused by challenging doses of NTG in the groups treated with NTG during 4 and 8 days. The dose of SG-75 required to induce a tolerance was about $1 / 20$ that of NTG.

Tolerance and vascular smooth muscle: Aortic strips incubated with SG-75 $\left(10^{-4} \mathrm{M}\right)$ showed no decrease in sensitivity to SG-75: the dose-response curve to the SG-75 challenging doses was not shifted in the strips incubated for $30 \mathrm{~min}$ with SG-75 (Figs 4 and 5). whereas that to the NTG challenging doses was shifted markedly to 


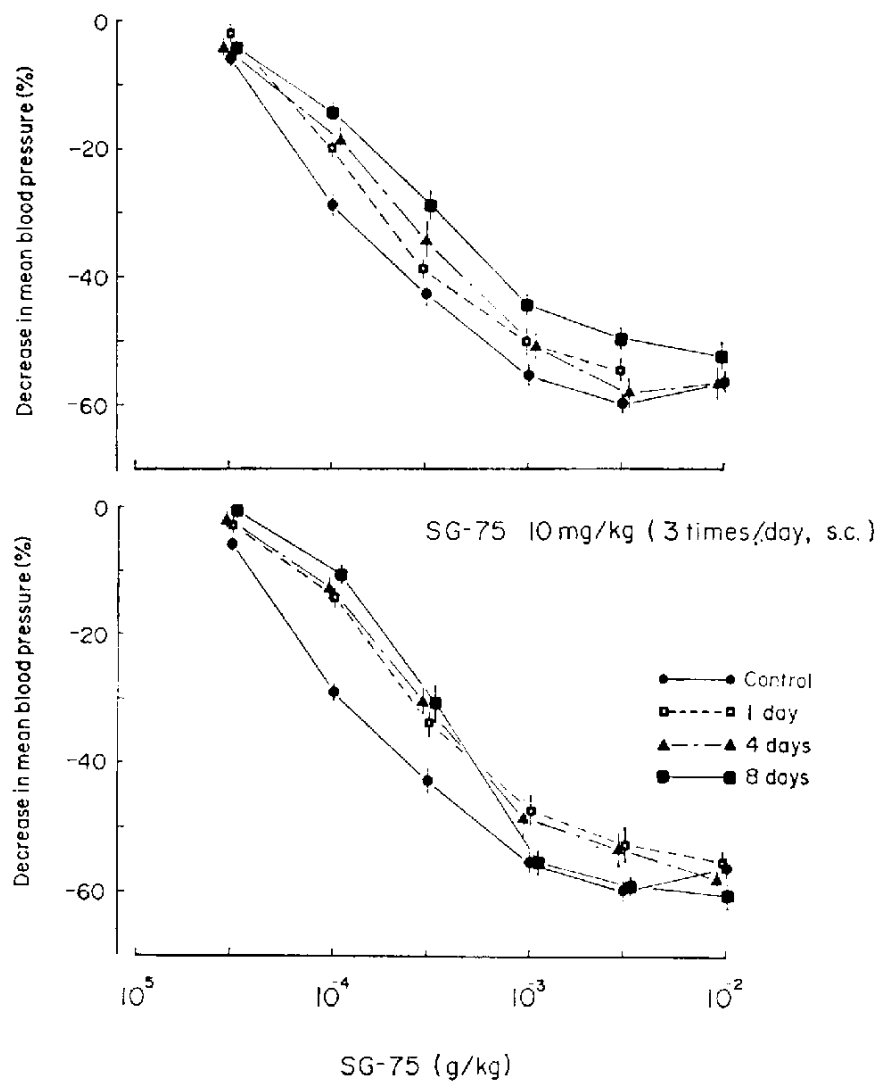

Fig. 2. Dose-response relationship for SG-75-induced blood pressure depression. Rats were pretreated s.c. with SG-75 for the number of days shown. Sixteen to eighteen hr after the last dose, challenging doses of SG-75. were administered i.v. Each point represents means $\pm S$. E. of 8 experiments.

the right in the preparation incubated for 30 min with NTG $\left(10^{-4} \mathrm{M}\right)$ (Figs. 6 and 7 ). Since alcohol solution of NTG was used for incubation, aortic strips were incubated for $30 \mathrm{~min}$ with $0.1 \%$ alcohol solution, equivalent to alcohol concentration of NTG solution $\left(10^{-4} \mathrm{M}\right)$. There were no significant differences between the groups incubated or not incubated with $0.1 \%$ alcohol solution with regard to the responsiveness to challenging doses of NTG (not shown).

The aortic strips were tested to determine if cross-tolerance was developed between SG-75 and NTG. A typical experiment is illustrated in lower part of Fig. 6. The activity of SG-75 to develop cross-tolerance to NTG was studied by incubating the strips for $30 \mathrm{~min}$ with SG-75 $\left(10^{-4} \mathrm{M}\right)$. The dose-response curve to the NTG challenging doses was not shifted in the strips incubated with SG-75 (Fig. 7). Similar results were obtained from the dose-response curve to the SG-75 challenging doses in the preparations incubated with NTG $\left(70^{-4} \mathrm{M}\right)$ (Fig. 5).

The $\mathrm{pD}_{2}$ and $\mathrm{pD}_{5}$ values of NTG (in the preparation incubated with NTG) were 4.72 and 5.49, respectively, while the values of 
NTG $10 \mathrm{mg} / \mathrm{kg}$ ( 3 times/day, s.c.)

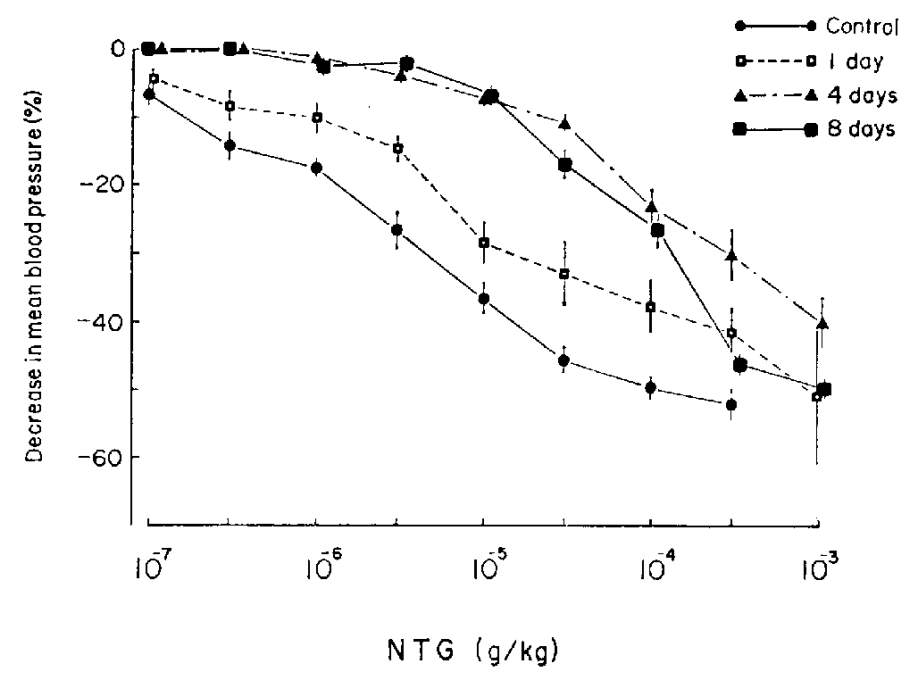

Fig. 3. Dose-response relationship for nitroglycerin (NTG)-induced blood pressure depression. Rats were treated with NTG $(10 \mathrm{mg} / \mathrm{kg}$, s.c.) for the number of days shown. Sixteen to eighteen hr after the last NTG s.c. injection challenging doses of NTG. were administered i.v. Each point represents means \pm S.E. of 8 experiments.

control (in the preparation not incubated) were 6.47 and 7.51 (Table 2). The NTGtreated preparations showed at least 104fold decrease in responsiveness to NTG.

\section{DISCUSSION}

The present study revealed that SG-75 developed only slight tolerance in vivo, but no tolerance in vitro. On the other hand. NTG developed marked tolerance in vivo as well as in vitro. This finding, pertaining to the development of NTG tolerance, is consistent with the results of NTG reported by Needleman (8). One of the possible causes of drug desensitization is accumulation of the drug or its metabolites at the site of action. Needleman (8) showed that in blood pressure response, intact rats were tolerant 16 to $18 \mathrm{hr}$ after the last NTG s.c. administration at a time when NTG was not detected in the body. He presumed that unmeasurably small amounts of NTG could be bound at the site of action. According to the previous report (13), the plasma level of SG-75 and its metabolite, even in a single dose of $5 \mathrm{mg} / \mathrm{kg}$ of SG-75, administered p.o. to rats was maintained over $8 \mathrm{hr}$. In view of this, the afore-mentioned explanation for NTG tolerance may apply to the development of tolerance in vivo to SG-75.

Needleman and Johnson (9) hypothesized that organic nitrates react with reduced $\mathrm{SH}$ groups in the vascular smooth muscle receptor leading to the formation of a disulfide linkage and the release of inorganic nitrite. This reaction converts the nitrate receptor to the disulfide form which presumably has a lower affinity for NTG. Therefore, they suggested the possibility that this type of phenomena may be responsible for other organic nitrates tolerance.

SG-75 possesses a nitrate moiety in the chemical structure, but unlike NTG showed no evidence in vitro, that a tolerance had 

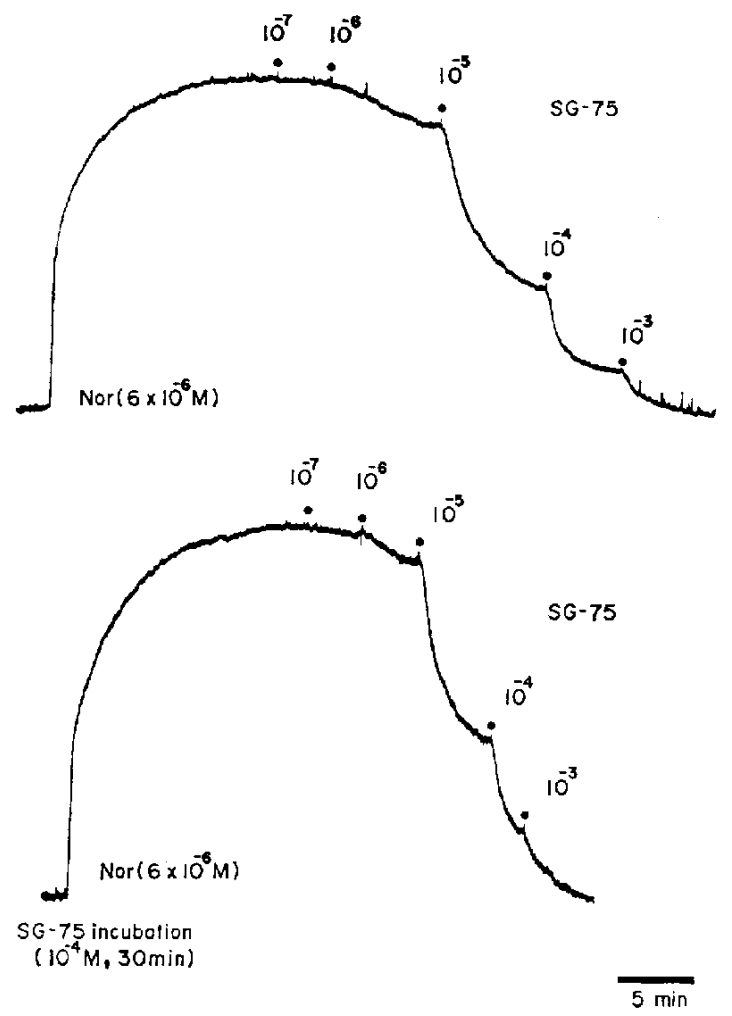

Fig. 4. Actual tracings of response of rat aorta strips to $S G-75$ in the preparation incubated (lower part) or not incubated (upper part) for $30 \mathrm{~min}$ at $37^{\circ} \mathrm{C}$ with SG-75 $\left(10^{-4} \mathrm{M}\right)$. The aorta strips were contracted with norepinephrine (Nor) $\left(6 \times 10^{-6} \mathrm{M}\right)$ and relaxed by challenging doses of SG-75. Challenging doses of SG-75 (M) were added cumulatively to the bath fluid.

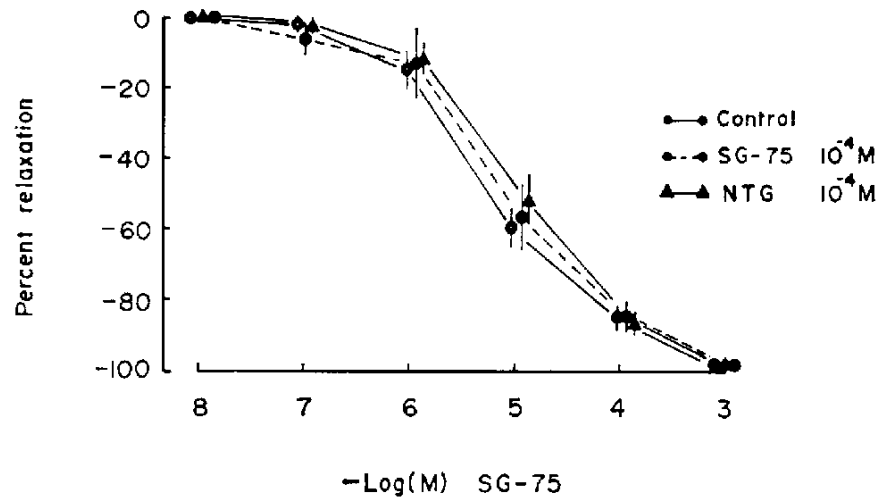

Fig. 5. Dose-response relationships of rat aorta strips to challenging doses of SG-75 after SG-75 or nitroglycerin (NTG) treatment. Strips were incubated for $30 \mathrm{~min}$ at $37^{\circ} \mathrm{C}$ in the presence of SG-75 $\left(10^{-4} \mathrm{M}\right)$ or NTG $\left(10^{-4} \mathrm{M}\right)$. Contractions induced by $6 \times 10^{-6} \mathrm{M}$ norepinephrine were taken as $100 \%$ and then relaxations were produced by the successive addition of increasing dases of SG-75. Each point represents means \pm S.E. of 5 experiments. 

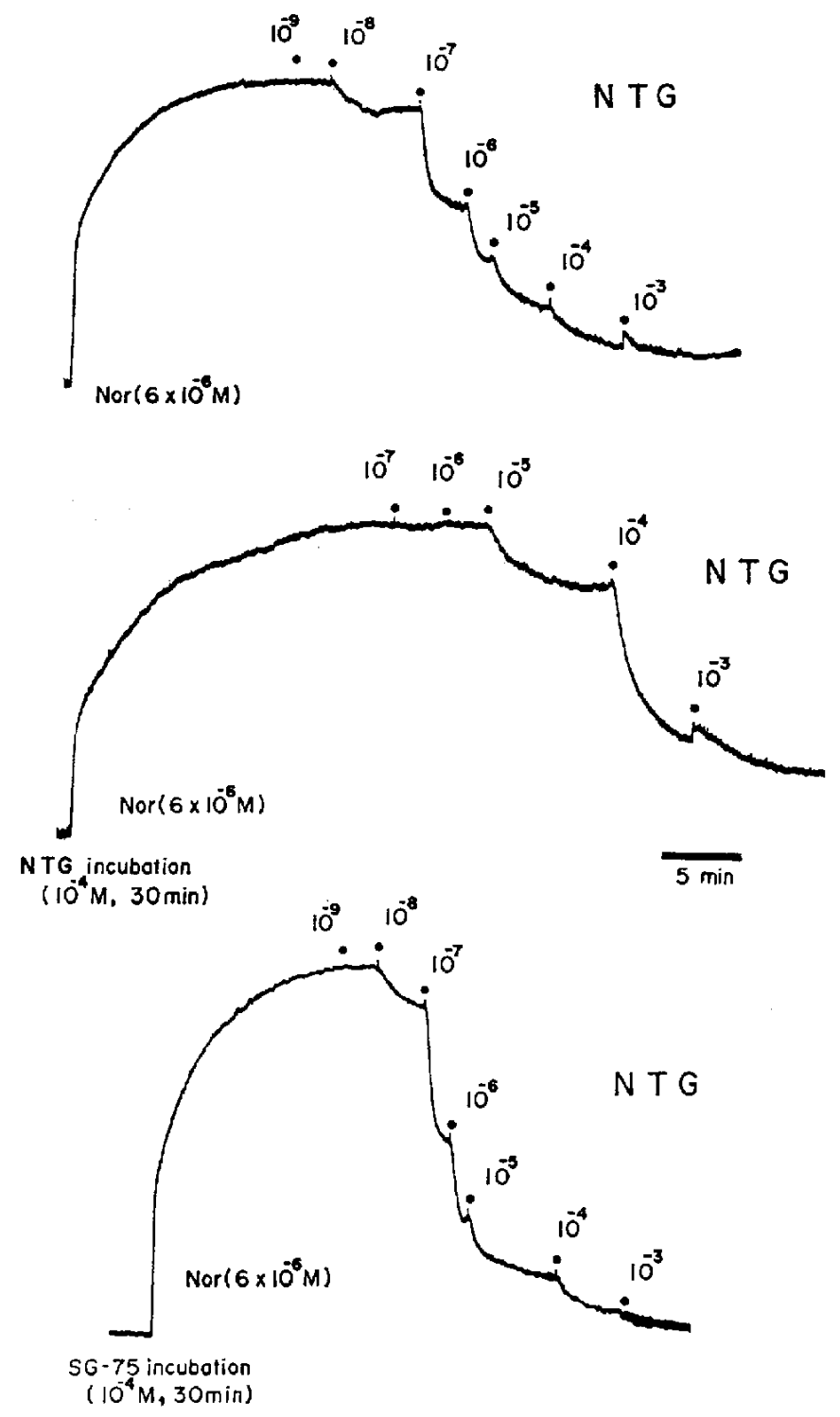

Fig. 6. Actual tracings of response of rat aorta strips to nitroglycerin (NTG). The aorta strips were contracted with norepinephrine (Nor) $\left(6 \times 10^{-6} \mathrm{M}\right)$ and relaxed by challenging doses of NTG. Upper part, control (not incubated): middle part, incubated for 30 min with NTG $\left(10^{-4} \mathrm{M}\right)$; lower part, incubated for $30 \mathrm{~min}$ with SG-75 $\left(10^{-4} \mathrm{M}\right)$. Challenging doses of NTG (M) were added cumulatively to the bath fluid.

developed. When rat thoracic aorta strips were incubated for $30 \mathrm{~min}$ at $37^{\circ} \mathrm{C}$ in an ${ }^{14} \mathrm{C}-\mathrm{SG}-75$ Tris buffer solution, ${ }^{14} \mathrm{C}-\mathrm{SG}-75$ bound with the tissues, but could be readily washed out (unpublished data by Dr. Y. Hinohara). Thus, the binding of SG-75 with the tissue seems to be reversible. On the basis of the finding that there was no cross tolerance between SG-75 and NTG, it is also suggested that $S G-75$ may be different from NTG, pertaining to the mode of binding to the receptors or the site and mechanism of 


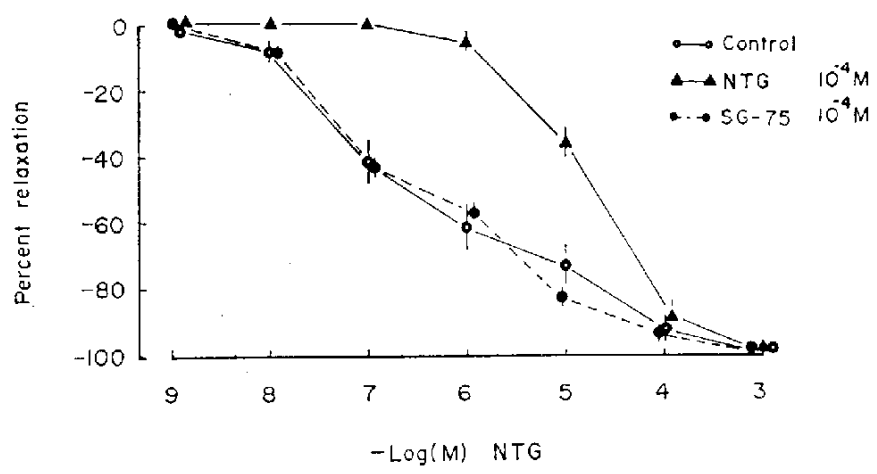

Fig. 7. Dose-response relationships of rat aorta strips to challenging doses of nitroglycerin (NTG) or SG-75 treatment. Strips were incubated for $30 \mathrm{~min}$ in the presence of NTG $\left(10^{-4} \mathrm{M}\right)$ or SG-75 $\left(10^{-4} \mathrm{M}\right)$. Contractions induced by $6 \times 10^{-6}$ norepinephrine were taken as $100 \%$ and then relaxations were produced by the successive addition of increasing doses of NTG. Each point represents means \pm S.E. of 5 experiments.

Table 2. $\mathrm{PD}_{2}^{\prime}$ and $\mathrm{PD}_{5}^{\prime}$ values of $\mathrm{SG}-75$ and nitroglycerin (NTG) in isolated thoracic aortae of rats

\begin{tabular}{clccc}
\hline & Drugs & Control & \multicolumn{2}{c}{$\begin{array}{c}\text { After incubation for } 30 \mathrm{~min} \\
\text { with each drug }\left(10^{-4} \mathrm{M}\right) \\
\mathrm{SG}-75\end{array}$} \\
\hline $\mathrm{PD}_{5}^{\prime}$ & $\mathrm{SG}-75$ & $5.75 \pm 0.20$ & $\mathrm{NTG}$ \\
\hline & $\mathrm{NTG}$ & $7.51 \pm 0.21$ & $7.85 \pm 0.19$ & $5.75 \pm 0.20$ \\
$\mathrm{PD}_{2}{ }_{2}$ & $\mathrm{SG}-75$ & $5.21 \pm 0.14$ & $5.20 \pm 0.29$ & $5.08 \pm 0.15$ \\
& $\mathrm{NTG}$ & $6.47 \pm 0.37$ & $6.55 \pm 0.13$ & $4.72 \pm 0.09^{* *}$ \\
\hline
\end{tabular}

Values are represented as mean \pm S.E. of 5 expcriments.

**P<0.01, significantly different from control values.

action.

Acknowledgement: We express thanks to Mrs. E. Suzuki for typing the manuscript.

\section{REFERENCES}

1) Uchida, $Y$, Yoshimoto, N. and Murao, S.: Effect of 2-nicotinamidethyl nitrate (SG-75) on coronary circulation. Japan. Heart J. 19, 112 124 (1978)

2) Nakagawa, Y., Takeda, K., Katano, Y., Tsukada, T., Kitagawa, T., Otorii, T. and Imai, S.: Effects of 2-nicotinamidoethyl nitrate on the cardiovascular system. Japan. Heart J. 20, 881-895 (1979)

3) Taira, N., Satoh, K., Yanagisawa, T., Imai, Y. and Hiwatari, M.: Pharmacologica! profile of a new coronary vasodilator drug, 2-nicotin- amidoethyl nitrate (SG-75). Clin. exp. Pharmacol. Physiol. 6, 301-316 (1979)

4) Sakai, K., Shiraki, Y. and Nabata, H.: Cardiovascular effects of a new coronary vasodilator. $\mathrm{N}$-(2-hydroxyethyl)nicotinamide nitrate (SG75): Comparison with nitroglycerin and diltiazem. J. Cardiovascular Pharmacol. 3. 139-150 (1981)

5) Stewart, D.D.: Tolerance to nitroglycerin. J.A.M.A. 44, 1678-1679 (1905)

6) Crandall, L.A., Leake, C.D., Loevenhart, A.S. and Muehlberger, C.W.: Acquired tolerance to and cross tolerance between the nitrous and nitric acid esters and sodium nitrite in man. $J$. Pharmacol. exp. Ther. 41, 103-119 (1931)

7) Schelling, J. and Lasagna, L.: A study of crosstolerance to circulatory effects of organic nitrates. Clin. Pharmacol. Ther. 8, 256-260 (1967) 
8) Needleman, P.: Tolerance to the vascular effects of glyceryltrinitrate, J. Pharmacol. exp. Ther. 171, 98-102 (1970)

9) Needleman, P. and Johnson, E.M. Jr.: Mechanism of tolerance development to organic nitrates. J. Pharmacol. exp. Ther. 184, 709-715 (1973)

10) Bogaert, M.G.: Tolerance towards glyceryltrinitrate (Trinitrin) in rabbits. Archs int. Pharmacodyn. Thér. 172, 228-230 (1968)

11) Crandall, L.S.: The fate of glyceryl trinitrate in the tolerant and non-tolerant animal. J. Pharmacol. exp. Ther. 48, 127-140 (1933)

12) Bogaert, M.G. and De Schepdryver, A.F.:
Tolerance towards glyceryl trinitrate (Trinitrin) in dogs. Archs int. Pharmacodyn. Thér. 171, 221-224 (1968)

13) Sakai, K., Ohba, Y., Akima, M., Kamiyama, H., Hinohara, Y. and Nakano, H.: Pharmacodynamic and metabolism studies on a new coronary vasodilator. $\mathrm{N}$-(2-hydroxyethyl) nicotinamide nitrate (SG-75). Japan. J. Pharmacol. 30, $881-890(1980)$

14) Van Rossum, J.M.: Cumulative dose-response curves II. Technique for the making of doseresponse curves in isolated organs and the evaluation of drug parameters. Archs int. Pharmacodyn. Thér. 143, 299-330 (1963) 